\title{
Performance evaluation of VLC system using new modulation approach
}

\author{
Norizan Binti Mohamed Nawawi ${ }^{1}$, Anuar M. S. ${ }^{2}$, M. N. Junita ${ }^{3}$, S. R. Abdullah ${ }^{4}$ \\ ${ }^{1,2,3}$ School of Computer and Communication Engineering, UNIMAP, Perlis, Malaysia \\ ${ }^{4}$ Jabatan Kejuruteraan Electrik, Politeknik Tuanku Syed Sirajuddin, Perlis, Malaysia
}

\begin{tabular}{l} 
Article Info \\
\hline Article history: \\
Received Dec 12, 2018 \\
Revised Jan 30, 2019 \\
Accepted Feb 7, 2019 \\
\hline Keywords: \\
Catenated-OFDM \\
Modulation technique \\
OFDM \\
OWC \\
VLC
\end{tabular}

\begin{abstract}
We propose a modified OFDM modulation based on multiband scheme for visible light communications (VLC) system. The method called catenated-OFDM VLC system can efficiently boost the propagation distance and combat multipath induced the inter symbol interference and inter carrier interference. Design parameters such as number of optical bands, input power, distance and data rate are varied to see their effect on the system performances. Simulation analysis is done using Optisys software Ver. 11.0. The results show that the proposed system offers a good performance at longer transmission distance of $12 \mathrm{~m}$ for input power of $2 \mathrm{dBm}$ in case of Band=3 with $10 \mathrm{Gbps}$ data rate. BER curves also indicates that the proposed system can be operated at very high data rate of $15 \mathrm{Gbps}$. This exhibits the ability of the proposed system to be one of the candidate for future optical wireless communication system.
\end{abstract}

Copyright $(0) 2019$ Institute of Advanced Engineering and Science. All rights reserved.

\section{Corresponding Author:}

Norizan Binti Mohamed Nawawi,

School of Computer and Communication Engineering,

UNIMAP, 02600 Perlis, Malaysia.

Email: norizan1123@gmail.com

\section{INTRODUCTION}

Recently, optical wireless communication (OWC) came along taking the attention because of several importance characteristics such as large bandwidth, high security, low cost, and license free operation [1-2]. Although OWC has only recently been gaining interest in transmission system, it has a long history of existence. Optical wireless communications have been used long before radio communications were first considered. The first implementation of OWC started in 1880, when Alexander Graham Bell and his assistant invented wireless optical technology in the form of photo-phone [3-4]. This instrument was used to transmit a human voice hundreds of meters by modulating the sunlight. However, over the last century the communication through radio frequency medium has been the preferred choice to transmit data wirelessly. Only now when there are shortages in capacity for wireless data communications, it necessary to explore and consider other alternatives like wireless optical communication as a candidate for widespread wireless communications applications [2].

Optical wireless especially Visible Light Communication (VLC) can be a potential candidate solution for 5G networks [5]. The VLC system has been investigated for about one and half decade and received a lot of interest [6]. VLC systems have more flexibility and integrity than other communication systems in many regards. Since the medium for transmission in VLC systems is visible light and not radio waves that can penetrate walls, the issue of security is inherently solved because light cannot leave the room, containing data and information in one location. There is no way to retrieve and access the information unless a user is in a direct path of the light being used to transmit the data.

VLC technology encounters several challenges in the implementation level. One of the major challenge in VLC systems has been in improving transmission speed with high spectral efficiency. Similar to 
other broadband wireless access network, VLC is aimed to allow high data rate communication between users. A maximum speed of 662 Mbps of on-off-keying (OOK) VLC system was reported in [7] using a high power red-green-blue (RGB) type of light emission diode (LED) with post-equalizing technique for an optical receiver. Unfortunately, the VLC with OOK data formatting approaches still leads to poor efficiency of optical wireless communication for future broadband access network [8]. The single-carrier modulation schemes did not handle inter-symbol interference (ISI) properly which resulted in nonlinear frequency response of VLC [9]. Hence, a suitable and good modulation technique may lead to increase the speed (> 1 Gbps) of the overall system. Compared with non-return-to-zero (NRZ) OOK modulation, orthogonal frequency division multiplexing (OFDM) modulation attracts much attention due to its advantage of high spectral efficiency, reduced the complexity in equalizers [10] and might be a promising alternative for high-speed VLC systems [11]. On the other hand, the visible laser diodes (LDs) reveal high direct modulation speed and high pumping efficiency with the absence of efficiency droop effect, which becomes a research spotlight for developing alternative VLC systems [8]. Hence, there are still room of improvement in modulation scheme that could improve bandwidth efficiencies of the existing modulation scheme while maintaining the high data rates system.

This paper aims to evaluate the performance of a new modulation scheme in VLC domain based on multiband OFDM to achieve large bandwidth efficiencies while maintaining the high data rates system. The rest of the paper is organized as follows. In section 2, we describe the principle operation of modified OFDM scheme named catenated-OFDM for VLC systems. The simualtion and theoretical analysis are described in this section. Section 3 presents the results and discussion for catenated-OFDM VLC followed by the concluding remarks in Section 4.

\section{SYSTEM PRINCIPLE OPERATION}

The development of proposed system model for catenated-OFDM VLC system is based on modifying the conventional OFDM by adding more OFDM signal to be transmitted at the same time. Figure 1 shows the proposed setup of a new catenated OFDM modulation technique. Generally, this new modulation technique employs a transmitter and a receiver to send more than one OFDM band at a same time. An electrical adder is used to combine all OFDM bands in electrical domain at their respective frequencies. The total OFDM bands are then carried by visible laser diode through VLC channel to be detected by photodetector. In the receiver part, the electrical band pass filters are used to extract back the received signals to their individual frequencies band.

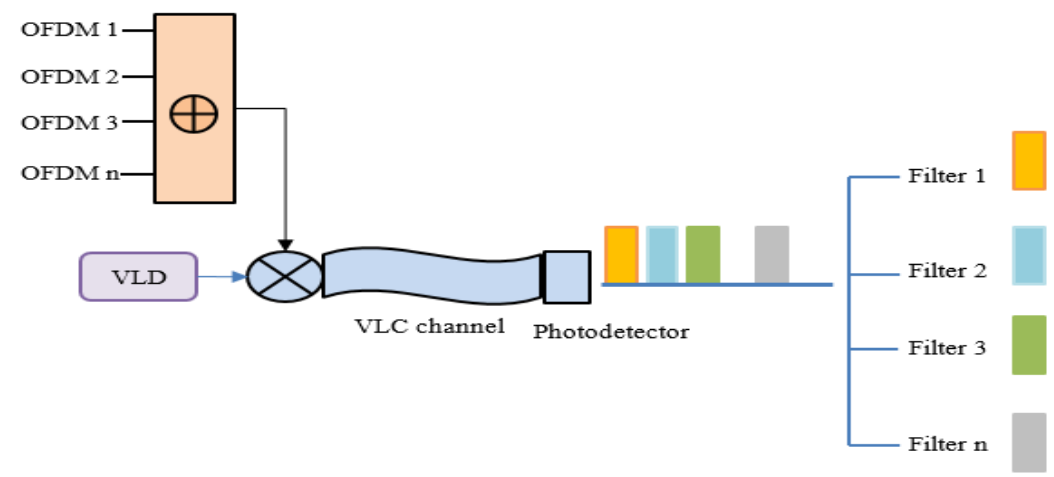

Figure 1. Proposed setup for Catenated-OFDM modulation technique

The simulation approach is an another analysis solution when there is limitation in hardware and experimental availability. It also necessary for validation and optimization analysis before entering the next stage; implementation in real time condition. In this work, the Optisystem Software (Version 11) was used for simulation. The Optisystem is employed to build the proposed models of catenated-OFDM modulation technique for VLC system. It is also used to build the proposed model to combined with OCDMA system based on ZCC code properties. Through the simulation it allows each of the design modulation sequence system will be tested using varying specific sets of designing parameters such as modulation index, number of subcarriers, transmission distance and data rate. Overall performance is study and characterized mainly by the BER, SNR, effective power, modulation index number of bands, number of users, code weight and code length. 
Figure 2 shows the simulation diagram of catenated-OFDM visible light communication system. Catenated-OFDM VLC transceiver system consists of a transmitter and a receiver. Broadband visible light source is used as carrier to carried the catenated-OFDM data at $480 \mathrm{~nm}$ wavelength. In order to evaluate a fair comparison performance, the other simulation parameters are set close to theoretical parameters. The two boxes indicate the catenated-OFDM subsystem and receiver components for one channel. The thermal noise coefficient was set to $15 \times 10-24 \mathrm{~W} / \mathrm{Hz}$ for each of photodetectors, and the dark current was set to $9 \mathrm{nA}$. Figure 3 indicates the components inside the subsystem in the first box of Figure 1. Each subcarrier of OFDM signal is encoded with QAM symbol and generated at their respective center frequency. Then, the generated band is concatenated together using electrical adder before they are converted to optical signal. The receiver architecture displays in the second box of Figure 2. Rx_1 is a set of demodulators contain of QAM demodulator and OFDM demodulator which translate every carrier down to direct current. The signal is integrated with the symbol period to regenerate the data from that carrier. The same demodulator also demodulates the other carriers. As the OFDM carrier spacing equal to the reciprocal of the symbol period means that they will have a whole number of cycles in the symbol period leads to no interference contribution.

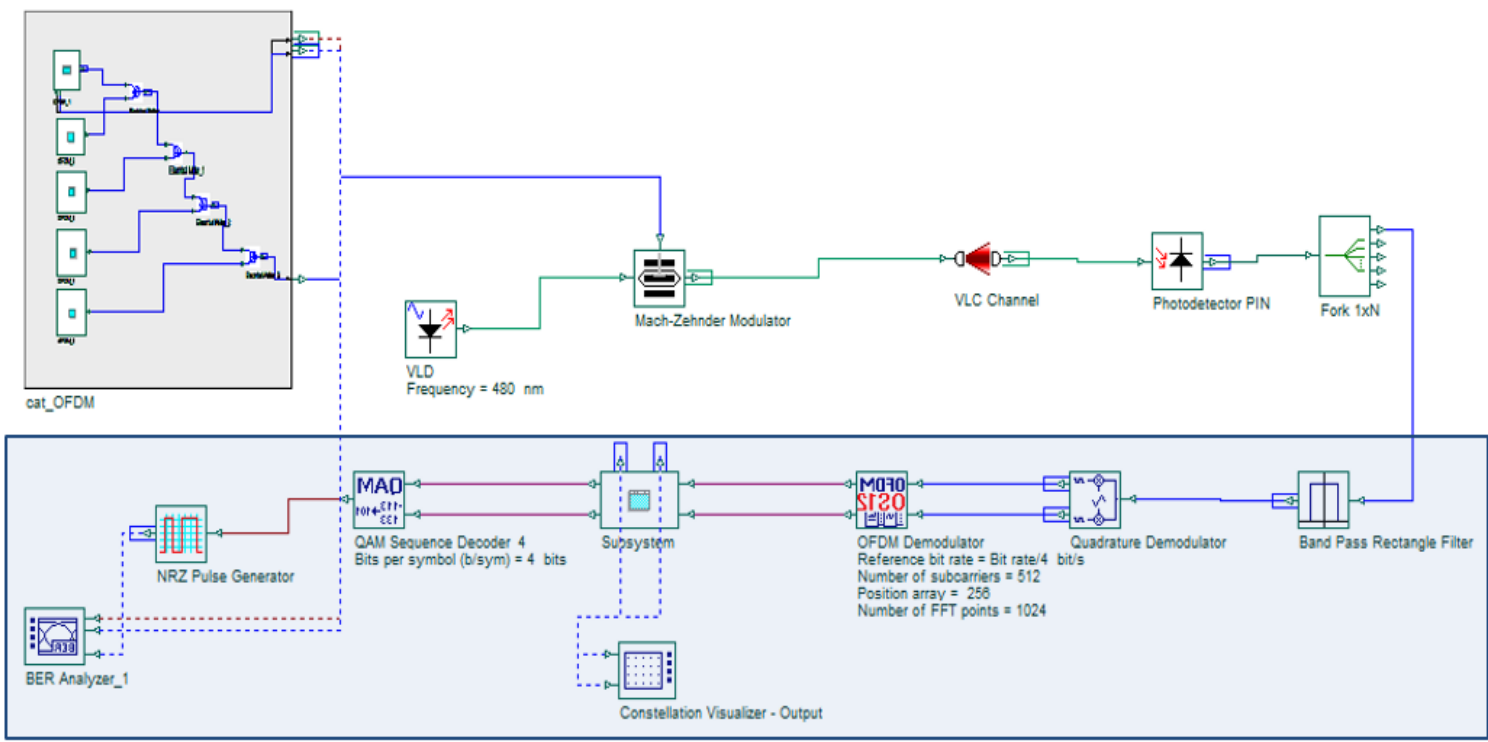

$\mathrm{Rx} 1$

Figure 2. The simulation diagram of Catenated-OFDM visible light communication system

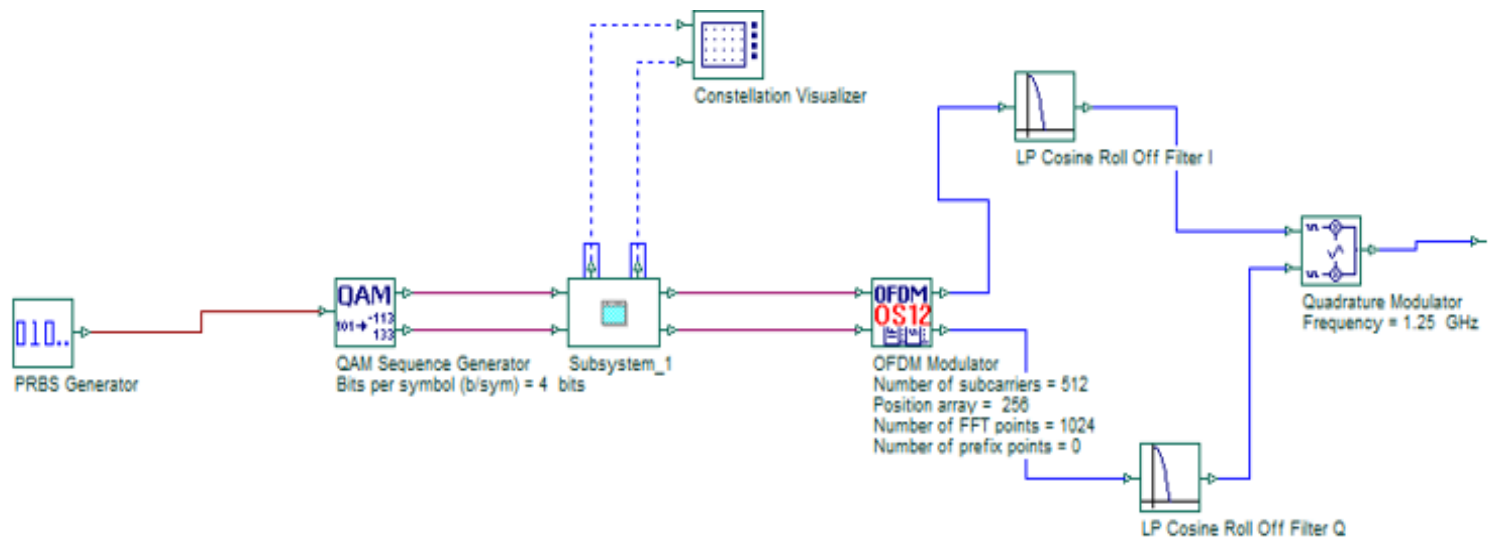

Figure 3. Catenated-OFDM for one band (see subsystem cat_OFDM in Figure 2)

The signal to noise ratio (SNR) and the BER of the system can be written as;

$$
S N R=\frac{R^{2} P_{r}^{2} c_{k}^{2} m_{n}^{2}}{2 e\left(R P_{r} c_{k} m_{n}\right) B+2 e\left(I_{r_{-} \text {ambient }} I_{2}\right) B+\frac{4 k T B}{R_{L}}}
$$


where $P_{r}$ is an effective power at receiver, $c_{k}$ is the OFDM information symbol, $m_{n}$ is the the modulation index of the $n$th band while $n$ is number of band, $e$ is the electron charge which equal to $1.6 \times 10 \mathrm{C}^{-19}, I_{r}$ and $I_{r_{-} a m b i e n t}$ are the generated signal and ambient currents in the photodetector, and $I_{2}$ is the noise bandwidth factor [12-13].

\section{RESULTS AND ANALYSIS}

In general, VLC is a short-range communication technology as its suffers from shadowing and atmospheric absorption. However, visible channel is a healthy environment and in the literature the VLC has gained a lot of research in order to improve the expected throughput at higher bit rate [14-18]. Simulation and theoretical results in this section are based on parameter listed in Table 1.

\begin{tabular}{cc} 
Table 1. Parameter list for simulation and theoretical \\
\hline Parameter & Power $(\mathrm{kW})$ \\
\hline Number of used subcarrier & 256 \\
Number of band & 1 to 5 bands \\
Modulation Mapping, M & $16-\mathrm{QAM}$ \\
Input Power & 0 and $2 \mathrm{dBm}$ \\
Number of samples & 65536 \\
Bit Rate & $10 \mathrm{Gbps}$ \\
Responsivity, $\mathrm{R}$ & 0.32 \\
Load Resistor, $\mathrm{R}_{\mathrm{L}}$ & 1030 \\
Electron charge, $\mathrm{e}$ & $1.6 \times 10-19 \mathrm{C}$ \\
Boltzmann's constant, $\mathrm{k}$ & $1.38 \times 10-23 \mathrm{~J} / \mathrm{K}$ \\
Absolute temperature, $\mathrm{T}$ & $300 \mathrm{~K}$ \\
\hline
\end{tabular}

Figure 4 shows the effect of transmission distance on the system performance at $10 \mathrm{Gbps}$ for different number of bands at input power of $0 \mathrm{dBm}$ and $2 \mathrm{dBm}$. The graph indicates that the shorter the transmission distance provides better BER performance than at longer transmission distance. This is happened due to the shadowing and atmospheric absorption effects become significant as increases the distance. For BER of $10^{-9}$, the cat-OFDM VLC system with $0 \mathrm{dBm}$ input power can go up to $2.5 \mathrm{~m}$ distance for $B$ and $=5$ and $4.5 \mathrm{~m}$ distance for Band=3, while when the input power increases to $2 \mathrm{dBm}$, the transmission distance is extended to $9.5 \mathrm{~m}$ and $12 \mathrm{~m}$ distance for $\mathrm{Band}=5$ and Band=3 respectively.

Figure 5 presents the effect of data rates on the system performance with respect to propagation distance. The simulation is done for 5 catenated bands at $1 \mathrm{Gbps}, 6.52 \mathrm{Gbps}$ and $10 \mathrm{Gbps}$ with fixed input power of $0 \mathrm{dBm}$. For this result, the transmission distance is varied from $1 \mathrm{~m}$ up to $24 \mathrm{~m}$. As can be seen, when the data rate increases, the transmission distance becomes shorter. At error floor $10^{-9}$, the maximum transmission distance is $2.5 \mathrm{~m}, 9 \mathrm{~m}$ and $21.5 \mathrm{~m}$ for $10 \mathrm{Gbps}, 6.52 \mathrm{Gbps}$ and $1 \mathrm{Gbps}$ respectively. In addition, at same distance of $9 \mathrm{~m}, \mathrm{BER}$ is increase when increases the data rates from 1 Gbps to 6.52 Gbps is 20 magnitudes of BER, and from $1 \mathrm{Gbps}$ to $10 \mathrm{Gbps}$ is about 25 magnitudes of BER. As the data rate increase, the bandwidth is increase. Higher levels of noise will be received, when bandwidth is larger and therefore the signal to noise ratio of the system will decrease.

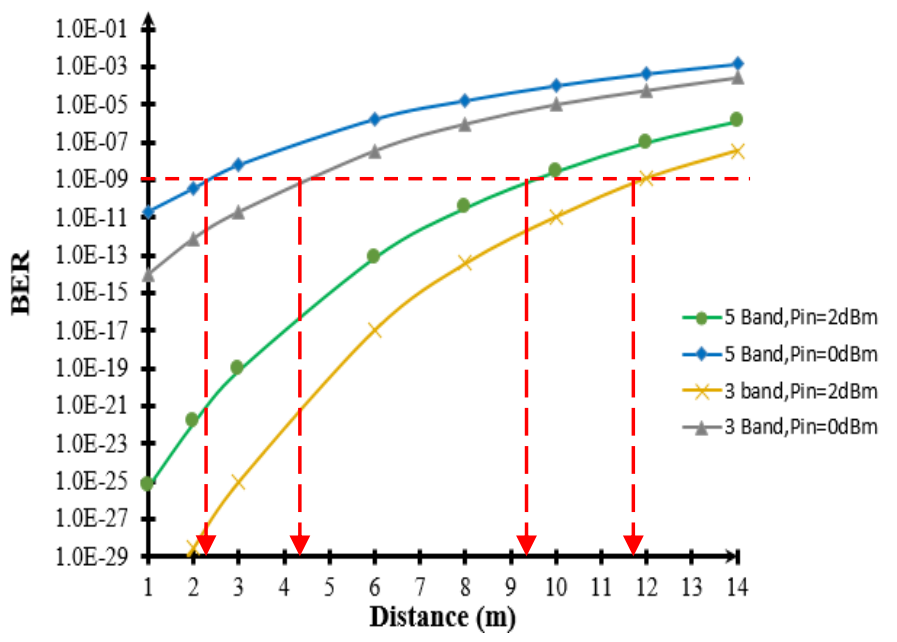

Figure 4. BER over distance (m) with different input power level for different bands 


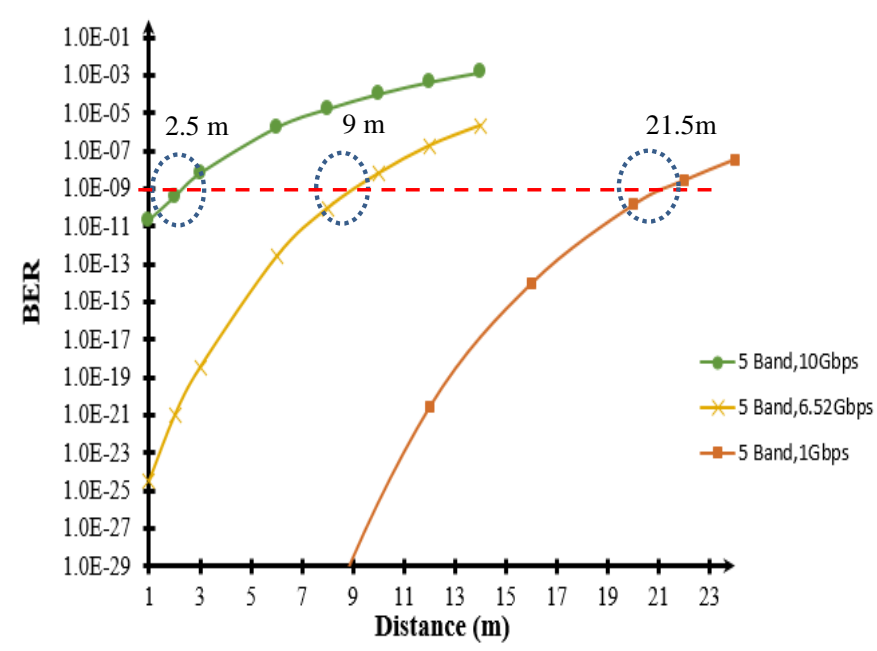

Figure 5. BER performance over transmission distance $(\mathrm{m})$ with different data rates

Further analysis is done and shown in Figure 6 to analyze the receiver sensitivity as bit rate and number of band varies. This result is based on numerical analysis in (2). From the graph, it indicates that the effective power is $-18.3 \mathrm{dBm},-17 \mathrm{dBm}$ and $-16 \mathrm{dBm}$ for Band=2 at $5 \mathrm{Gbps}, 10 \mathrm{Gbps}$ and $15 \mathrm{Gbps}$ respectively. Two different systems are compared for Band=2 at $15 \mathrm{Gbps}$ and Band $=5$ at $5 \mathrm{Gbps}$, the power penalty between two systems is $0.5 \mathrm{~dB}$ at $\mathrm{BER}=10^{-9}$. To get a same receiver sensitivity level of the system using cat-OFDM technique, it requires either a system with low number of band at higher bit rate or a system with high number of band at lower bit rate. In order to increase the spectral efficiency of the system, it is recommended to have more band with a lower bit rate rather than having fewer bands but with higher bit rate. It is also observed that, the system with a smaller number of band and lower bit rate cause lower BER performance and thus has higher receiver sensitivity.

$$
B E R=\frac{\sqrt{M}-1}{\sqrt{M} \log _{2} \sqrt{M}} \operatorname{erfc} \sqrt{\frac{3 \log _{2} M}{2(M-1)} S N R}
$$

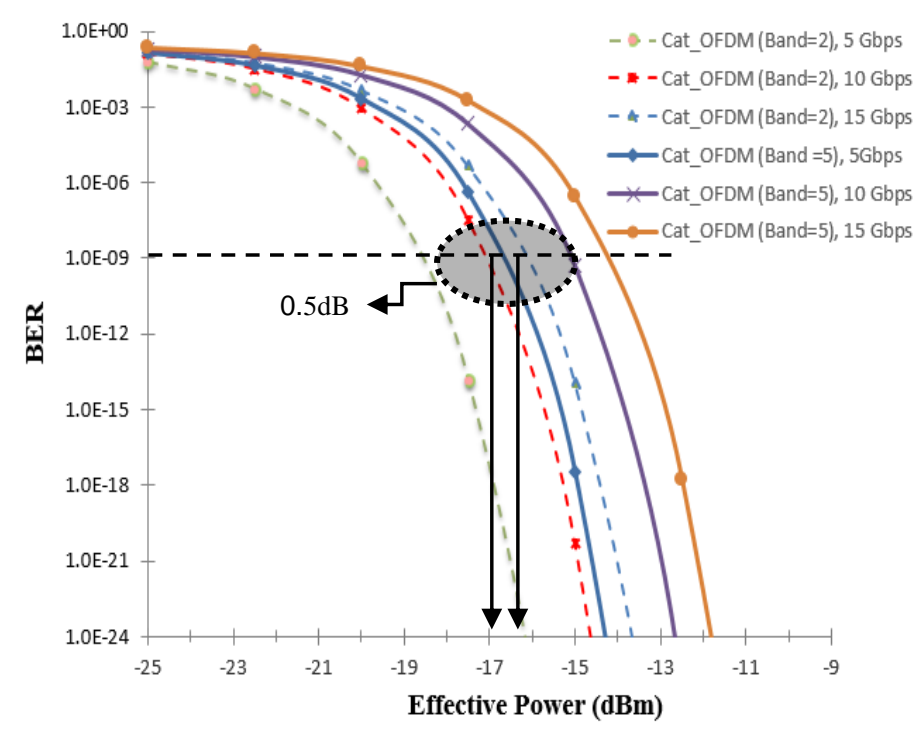

Figure 6. Performance of BER against the effective power as varies the bit rate for different number of band

\section{CONCLUSION}

In this paper, the performance of catenated-OFDM has been analyzed and presented for VLC 
system. Our work reveals that system performance in term of propagation distance is improved via the proposed catenated-OFDM VLC system based on the observation of BER curves over distance and effective received power. Furthermore, it indicates that the proposed system can be operated at higher data rate of 15 Gbps. This work can be one of the significant research spot for upcoming broadband optical wireless communication system.

\section{ACKNOWLEDGEMENTS}

This work has been funded and supported by the Department of Higher Education, Ministry of Higher Education Malaysia under Fundamental Research Grant Scheme, FRGS/2/2014/ICT06/UNIMAP/03/1 and School of Computer and Communication, Universiti Malaysia Perlis.

\section{REFERENCES}

[1] J. Gancarz, H. Elgala, and T. D. C. Little, "Impact of lighting requirements on VLC systems," IEEE Commun. Mag., vol. 51, no. 12, pp. 34-41, 2013.

[2] S. Gao, "Performance Study for Indoor Visible Light Communication," University of Ottawa, Canada, 2013.

[3] A. R. Ndjiongue, "Visible Light Communications ( VLC ) Technology," Wiley Encycl. od Electr. Electron. Eng., 2015.

[4] S. Dimitrov, "Analysis of OFDM-based intensity modulation techniques for optical wireless communications," University of Edinburgh, 2013.

[5] Z. Wang, F. Chen, W. Qiu, S. Chen, and D. Ren, "A two layer chaotic encryption scheme of secure image transmission for DCT precoded OFDM-VLC transmission," Opt. Commun., vol. 410, no. September 2017, pp. 94$101,2018$.

[6] D. C. O'Brien, "Visible Light Communications: Challenges and potential," IEEE Photonic Soc. 24th Annu. Meet. PHO 2011, vol. 3, pp. 365-366, 2011.

[7] N. Fujimoto and S. Yamamoto, "The fastest visible light transmissions of $662 \mathrm{Mb} / \mathrm{s}$ by a blue LED, $600 \mathrm{Mb} / \mathrm{s}$ by a red LED, and $520 \mathrm{Mb} / \mathrm{s}$ by a green LED based on simple OOK-NRZ modulation of a commercially available RGB-type white LED using pre-emphasis and post-equalizing techniques," Eur. Conf. Opt. Commun. ECOC, no. Cml, pp. 3-5, 2014.

[8] Y. C. Chi, D. H. Hsieh, C. T. Tsai, H. Y. Chen, H. C. Kuo, and G. R. Lin, "450-nm GaN laser diode enables high-speed visible light communication with 9-Gbps QAM-OFDM," Opt Express, vol. 23, no. 10, pp. 13051-13059, 2015.

[9] A. Khalid and H. M. Asif, "OCDMA and OSTBC based VLC transceiver design using NI cDAQ," Photonic Netw. Commun., pp. 1-12, 2017.

[10] F. Jiang, H. Deng, W. Xiao, S. Tao, and K. Zhu, “An ICA based MIMO-OFDM VLC scheme,” Opt. Commun., vol. 347, pp. 37-43, 2015.

[11] Y.-C. Chi, D.-H. Hsieh, C.-Y. Lin, H.-Y. Chen, C.-Y. Huang, J.-H. He, B. Ooi, S. P. DenBaars, S. Nakamura, H.-C. Kuo, and G.-R. Lin, "Phosphorous Diffuser Diverged Blue Laser Diode for Indoor Lighting and Communication," Sci. Rep., vol. 5, no. 1, p. 18690, 2016.

[12] T. Komine, S. Member, and M. Nakagawa, "Fundamental Analysis for Visible-Light Communication System using LED lights," IEEE Trans. Consum. Electron., vol. 50, no. 1, pp. 100-107, 2004.

[13] K. Cui, G. Chen, Z. Xu, and R. D. Roberts, "Line-of-sight visible light communication system design and demonstration," pp. 621-625.

[14] T. Komine, J. H. Lee, and S. Haruyama, "Adaptive Equalization System for Visible Light Wireless Communication Utilizing Multiple White LED Lighting Equipment,” IEEE Trans. Wirel. Commun., vol. 8, no. 6, pp. 2892-2900, 2009.

[15] C.-C. Wei, F.-M. Wu, Z.-Y. Chen, C.-T. Lin, Y.-S. Huang, Y.-J. (Ray) Chen, and S. Chi, "Indoor VLC System With Multiple LEDs of Different Path Lengths Employing Space-Time Block-coded DMT/CAP Modulation [Invited]," IEEE/OSA J. Opt. Commun. Netw., vol. 7, no. 3, pp. A459-A466, 2015.

[16] H. Chun, S. Rajbhandari, D. Tsonev, G. Faulkner, H. Haas, and D. O. Brien, "Visible Light Communication using Laser Diode based Remote Phosphor Technique," IEEE ICC 2015 - Work. Visible Light Commun. Netw., pp. 13921397, 2015.

[17] T. Hamanaka, X. Wang, N. Wada, A. Nishiki, and K. I. Kitayama, "Ten-user truly asynchronous gigabit OCDMA transmission experiment with a 511-chip SSFBG En/decoder,” J. Light. Technol., vol. 24, no. 1, pp. 95-101, 2006.

[18] M. Shi, C. Wang, H. Guo, Y. Wang, X. Li, and N. Chi, "A High-Speed Visible Light Communication System based on DFT-S OFDM," no. 2015, pp. 0-4, 2016. 


\section{BIOGRAPHIES OF AUTHORS}

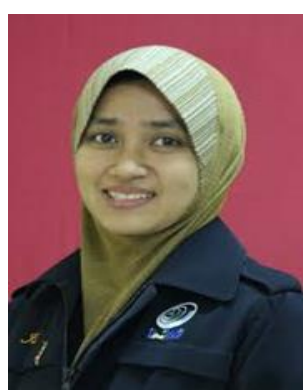

N. M. Nawawi received the B.Eng. degree in Electrical Engineering (Telecommunication) from Universiti Teknologi Malaysia (UTM), Malaysia in 2006; and the M.Eng. degree in ElectricalElectronic (Communication) Engineering from Universiti Teknologi Malaysia (UTM), Malaysia in 2008. Her research interests focus on optical communication, free space optic and optical wireless communication. She is lecturer at Universiti Malaysia Perlis (UniMAP) from 2008. Now, she is on study leave for her Ph.D study in the Communication Engineering from School of Computer and Communication Engineering, UniMAP, Malaysia.

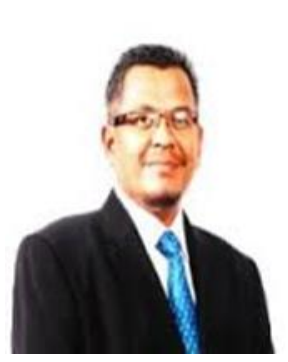

M. S. Anuar received his B.Sc. degree in Electrical and Electronic Engineering from Universiti Sains Malaysia (USM)/Malaysia, in 1995. He received the M.Sc. degree in Information Technology from Universiti Utara Malaysia (UUM)/Malaysia, in 2002, and Ph.D. degree in Communication Engineering from Universiti Malaysia Perlis (UniMAP)/Malaysia, in 2012. His research interests include optical fiber, free space optic, optical sensor, optical communication system, and wireless communication system. He is now an Associate Professor and Director of Qualification and Accreditation Unit in UniMAP, also, he is a Professional Engineer registered with the Board of Engineer Malaysia (BEM) in 2005.

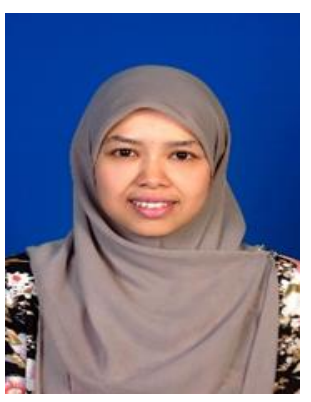

M. N. Junita received the B.Sc degree in Electrical Electronics Engiineering from Universiti Tenaga Malaysia in 2002 and the M.Sc degree in RF Communication System from University of Southampton, United Kingdom in 2005. In 2014, she received her $\mathrm{PhD}$. degree in Communication Engineering from Universiti Malaysia Perlis (UniMAP). Her research interest includes optical engineering and RF communication system. She is now an academician staff in School of Computer and Communication in UniMAP.

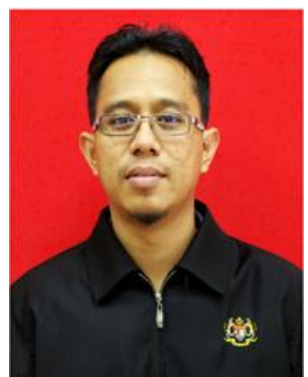

S. R. Abdullah received the B.Eng. degree in Electrical Engineering (Telecommunication) from Universiti Teknologi Malaysia (UTM), Malaysia in 2006; and the M.Eng. degree in ElectricalCommunication Engineering from Universiti Tun Hussain Onn (UTHM), Malaysia in 2013. His research interests focus on optical communication. He is lecturer at Politeknik Tuanku Syed Sirajuddin (PTSS) from 2009 under Electrical Engineering Department. 